\title{
Prevalence of Human Papillomavirus Type 18 DNA in Adenocarcinoma and Adenosquamous Carcinoma of the Uterine Cervix Occurring in Japan
}

\author{
Toru Tase, Shinji Sato, Yuichi Wada, Akira Yajima \\ and TaKashi OKagaKI* \\ Department of Obstetrics and Gynecology, Tohoku \\ University School of Medicine, Sendai 980 and \\ * Department of Laboratory Medicine and Pathology, \\ University of Minnesota Medical School, Minneapolis, \\ Minnesota, USA
}

Tase, T., Sato, S., Wada, Y., Yajma, A. and Oragaki, T. Prevalence of Human Papillomavimus Type 18 DNA in Adenocarcinoma and Adenosquamous Carcinoma of the Uterine Cervix Occurring in Japan. Tohoku J. exp. Med., 1988, 156 (1), 47-53 — To identify whether the incidence of human papillomavirus (HPV) type 18 DNA in adenocarcinoma and adenosquamous carcinoma is attributable to the histological types or geographical differences, the presence of HPV-16 and HPV-18 DNA in carcinoma of the uterine cervix from Japan were studied by in situ hybridization using tritium labeled HPV DNA probes. HPV-18 DNA was detected in 5 of 11 cases $(45 \%)$ of adenocarcinoma, one case of adenocarcinoma in situ and 2 of 3 cases of adenosquamous carcinoma. In contrast, HPV-16 DNA was detected in 2 of 11 cases $(18 \%)$ of adenocarcinoma, and 3 of 7 cases $(43 \%)$ of squamous cell carcinoma. Compared with our previous results (Tase et al. 1988), the present results imply that the prevalence of HPV-18 DNA in carcinoma of the uterine cervix is attributable rather to the histological differences than to the geographical differences.—uterine cervix; adenocarcinoma; human papillomavirus; in situ hybridization

Based on human papillomavirus (HPV) DNA homologies, thus far, more than 50 independent HPV types were detected, of which HPV-16, HPV-18, and HPV-33 have been said to be concerned with carcinoma of the uterine cervix (Boshart et al. 1985; Dürst et al. 1985; Beaudenon et al. 1986). However, their clinical behaviors have not been well known. Previously, we reported the prevalence of HPV-18 DNA in adenocarcinoma, adenosquamous carcinoma and HPV-16 DNA in squamous cell carcinoma (Tase et al. 1988). The presence of HPV-18 DNA in 5 to $25 \%$ of carcinoma of the uterine cervix has been reported in several papers (Boshart et al. 1985; Yoshikawa et al. 1985). Since histological diagnoses were not elaborated, it was not clear whether this tendency was attribut-

Received June 27, 1988; revision accepted for publication August 18, 1988. 
able to histological differences or geographical differences. In this study, using in situ hybridization technique with high sensitivity (detectable 3-5 homologous DNA copies/cell), the presence of HPV-16 and HPV-18 DNA in adenocarcinoma and adenosquamous carcinoma as well as squamous cell carcinoma from Japan were examined.

\section{Materials and Methods}

Eleven cases of adenocarcinoma, 3 cases of adenosquamous carcinoma and 7 cases of squamous cell carcinoma of the uterine cervix from 1980 to 1986 in the hospital of Tohoku University School of Medicine, in which the entire cervix of the hysterectomy specimen was available, were subjected to this study. Details of the procedure of in situ hybridization are described elsewhere (Hasse et al. 1984; Ostrow et al. 1987). Briefly, formalin-fixed paraffin-embedded tissues were cut into $5 \mu \mathrm{m}$ on Denhardt's treated slides, baked, deparaffinized and rehydrated, treated with $0.2 \mathrm{~N} \mathrm{HCl}$ and $0.153 \mathrm{M}$ triethanolamine hydrochloride, digested with proteinase $\mathrm{K}$ and ribonuclease $\mathrm{A} \& \mathrm{~T}_{1}$, and refixed in $5 \%$ paraformaldebyde. HPV-16 and HPV-18 DNA probes were prepared by nick translation with ${ }^{3} \mathrm{H}-\mathrm{dATP}$, ${ }^{3} \mathrm{H}$-dCTP, and ${ }^{3} \mathrm{H}$-dTTP to the specific activities of $0.5-1.1 \times 10^{8} \mathrm{dpm} / \mu \mathrm{g}$ DNA. Each HPV DNA probes was added to the tissues in hybridization solution $(0.6 \mathrm{M} \mathrm{NaCl}, 50 \%$ formamide, $10 \%$ dextran sulfate) and heat denatured at $80^{\circ} \mathrm{C}$ for 15 min and incubated at room temperature for 3 days. Tissue sections were washed in 50\% formamide containing nitrocellulose stripes for 3 days, coated with Kodak nuclear track emulsion, exposed for 4 weeks at $4^{\circ} \mathrm{C}$, developed and stained, and examined for the presence of silver grains of HPV DNA over the nuclei by light microscopy. Using this technique, 3-5 genome copies of homologous HPV DNA per cell can be detected (Ostrow et al. 1987).

\section{ResULTS}

HPV-18 DNA was detected in 5 of 11 cases (45\%) of adenocarcinoma, one case of adenocarcinoma in situ and 2 of 3 cases of adenosquamous carcinoma. HPV-16 DNA was detected in 2 of 11 cases $(18 \%)$ of adenocarcinoma and 3 of 7 cases $(43 \%)$ of squamous cell carcinoma (Table 1 ). There was no statistically significant difference in HPV-16 DNA positivity between adenocarcinoma and squamous cell carcinoma (chi square test: $0.05<p$ ). The silver grains of HPV DNA were confined to over the nuclei of the lesion of carcinoma and never extended to normal epithelium beyond the lesion (Figs. 1, 2 and 3).

TABLE 1. Detection of HPV-16 and HPV-18 DNA in carcinoma of the uterine cervix from Japan

\begin{tabular}{llll}
\hline \multicolumn{1}{c}{ Histological diagnosis } & $\begin{array}{c}\text { HPV DNA } \\
\text { positive }(\%)\end{array}$ & HPV-16 & HPV-18 \\
\hline Adenocarcinoma & $7 / 11(63 \%)$ & $2(18 \%)$ & $5(45 \%)$ \\
Adenocarcinoma in situ & $1 / 1$ & 0 & 1 \\
Adenosquamous carcinoma & $2 / 3$ & 0 & 2 \\
Squamous cell carcinoma & $3 / 7(43 \%)$ & $3(43 \%)$ & $0(0 \%)$ \\
\hline
\end{tabular}




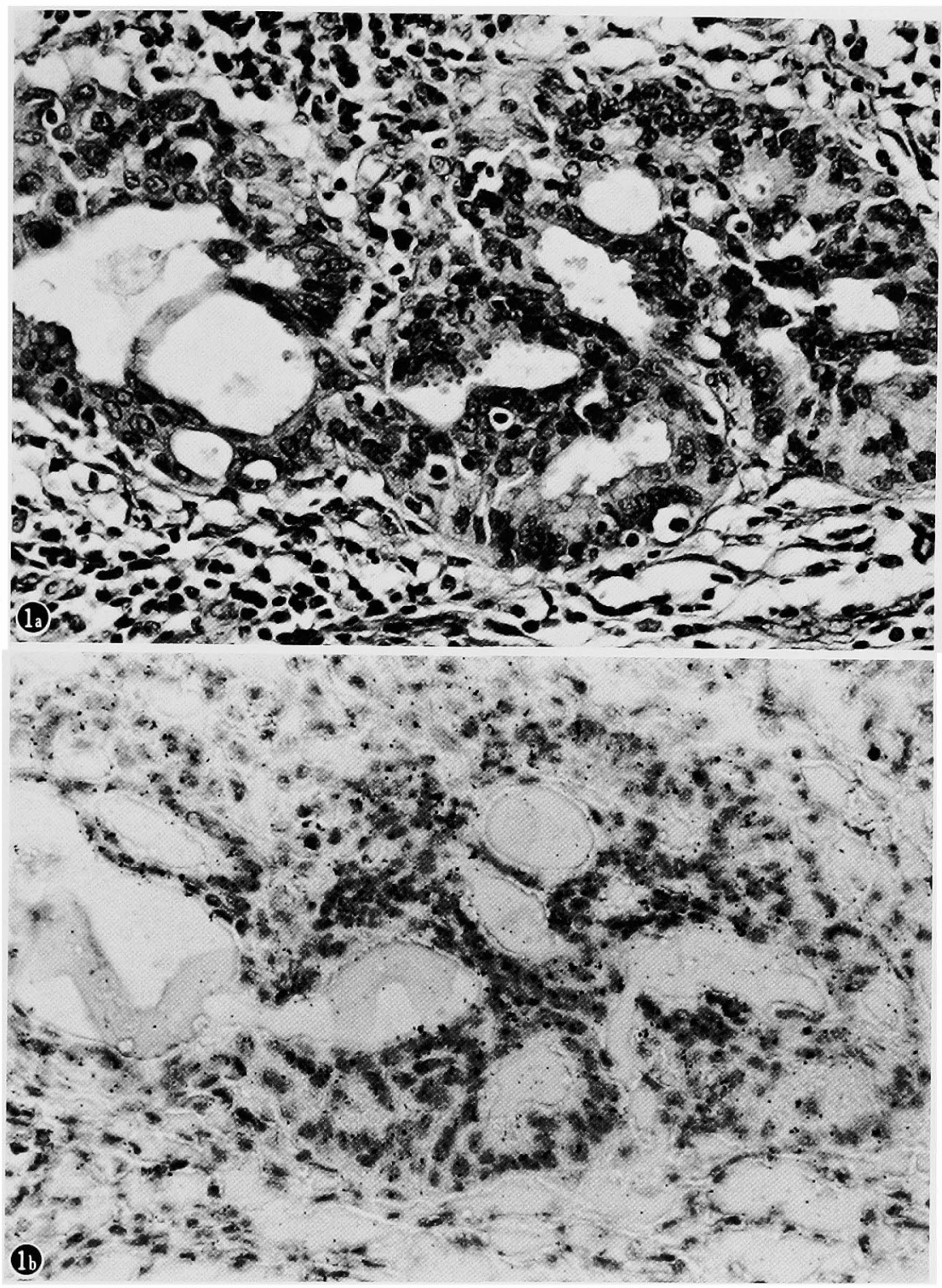

Fig. 1. Presence of HPV-18 DNA in adenocarcinoma of the uterine cervix by in situ hybridization, $\times 310$.

(a) Section stained with $\mathrm{H} \& \mathrm{E}$.

(b) Section hybridized with HPV-18 DNA probe. Silver grains of HPV-18 DNA are detected over the nuclei of adenocarcinoma with several foci of aggregation. 


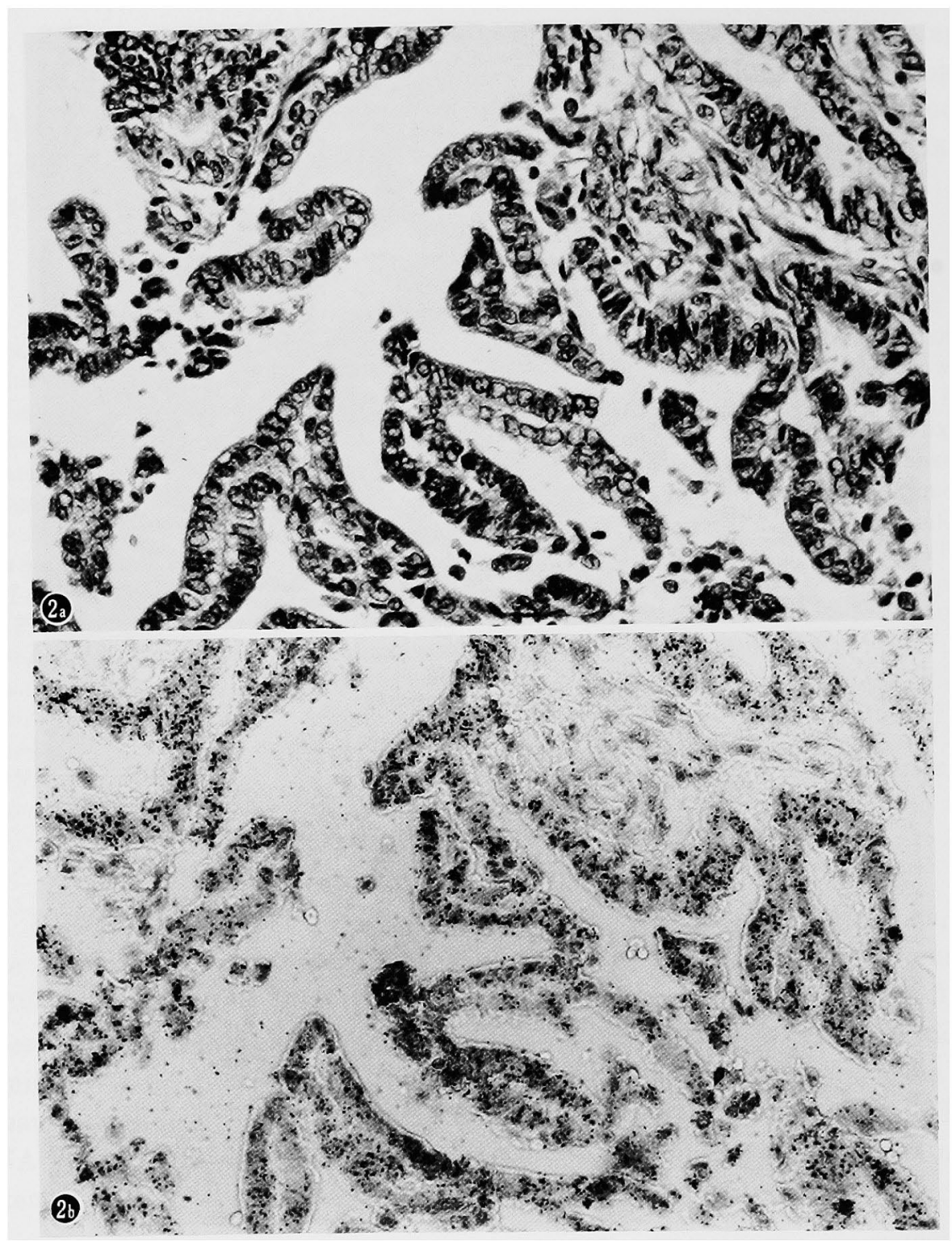

Fig. 2. Presence of HPV-16 DNA in adenocarcinoma of the uterine cervix by in situ hybridization, $\times 310$.

(a) Section stained with $\mathrm{H} \& \mathrm{E}$.

(b) Section hybridized with HPV-16 DNA probe. Silver grains of HPV-16 DNA are detected diffusely over the nuclei of adenocarcinoma. 


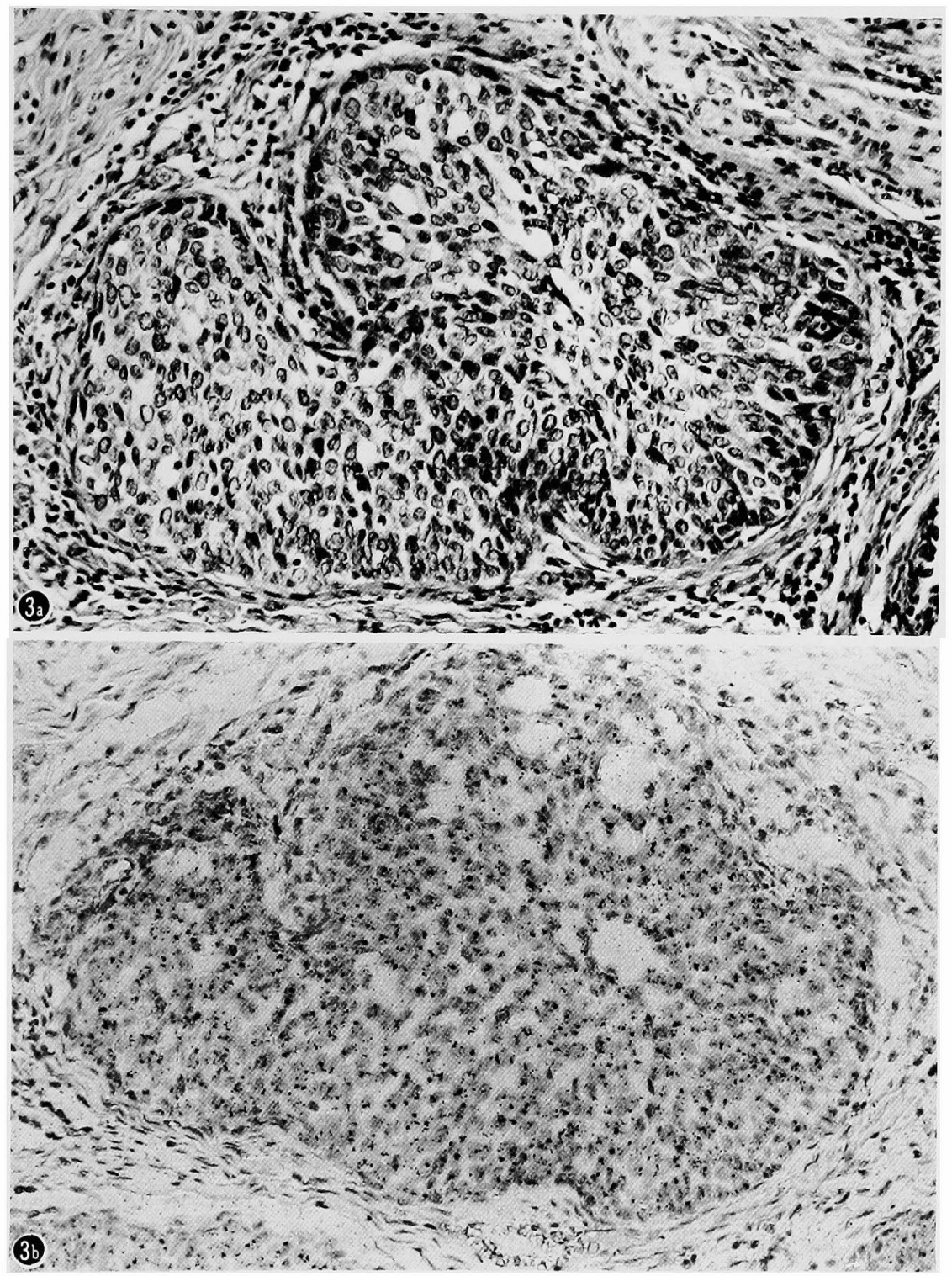

Fig. 3. Presence of HPV-16 DNA in squamous cell carcinoma of the uterine cervix by in situ hybridization, $\times 200$.

(a) Section stained with $\mathrm{H} \& \mathrm{E}$.

(b) Section hybridized with HPV-16 DNA probe. Silver grains of HPV-16 DNA are detected diffusely over the nuclei of squamous cell carcinoma. 


\section{Discussion}

The incidence of adenocarcinoma of the uterine cervix has increased especially in young women since the early 1970's in the United States (Peters et al. 1986; Schwartsz and Weiss 1986). The etiology and precursor lesions of adenocarcinoma of the cervix are not well known. Early detection of adenocarcinoma is sometimes difficult with the ordinary Papanicolaou smear test of the uterine cervix.

HPV, mainly HPV-16 DNA, was detected in squamous cell carcinoma of the uterine cervix and its precursor lesion, cervical intraepithelial neoplasia (CIN) (Dürst et al. 1983; Pater et al. 1986; Reid et al. 1987). Coexistence of CIN with adenocarcinoma (Maier and Norris 1980) or presence of HPV DNA in human established cell lines derived from adenocarcinoma or undifferenciated carcinoma of the uterine cervix (Boshart et al. 1985; Fukushima et al. 1985) suggested the possibility of the same etiologic role of HPV in adenocarcinoma as well as in squamous cell carcinoma.

HPV-18 DNA was first found in the biopsies of carcinoma of the uterine cervix from Germany and those from Brazil, Kenia and Uganda as well (Boshart et al. 1985). Since there was a difference in HPV-18 DNA incidence between the biopsies from Germany and those from Brazil, Kenia and Uganda, it has been wondered if this difference was attributed to geographical difference or any other factor such as histological types.

In our previous study (Tase et al. 1988), a large number of adenocarcinoma, adenosquamous carcinoma and squamous cell carcinoma from Minnesota (USA) were studied for HPV DNA by in situ hybridization. HPV-18 DNA was detected in $94 \%$ of HPV-positive adenocarcinoma and $50 \% \mathrm{HPV}$-positive adenosquamous carcinoma. HPV-16 DNA was detected in $6 \%$ of HPV-positive adenocarcinoma, $50 \%$ of HPV-positive adenosquamous carcinoma and all of HPV-positive squamous cell carcinoma. In this study, we obtained the same result that HPV-18 DNA or HPV-16 DNA was a prevalent type of HPV in adenocarcinoma or squamous cell carcinoma respectively as we had got in the previous study. We could not detected HPV-16 DNA in adenosquamous carcinoma, which may be due to the small number of cases. These results imply that HPV-16 and HPV-18 DNA exist separately, and that they have different favorite target cells. In other words, the prevalence of HPV-18 DNA in adenocarcinoma and HPV-16 DNA in squamous cell carcinoma is attributable rather to histological differences than to geographical differences.

\section{References}

1) Beaudenon, S., Kremsdorf, D., Croissant, O., Jablonska, S., Wainhobson, S. \& Orth, G. (1986) A novel type of human papillomavirus associated with genital neoplasias. Nature (Lond.), 321, 246-249. 
2) Boshart, M., Gissmann, L., Ikenberg, H., Kleinheinz, A., Scheurlen, W. \& zur Hauzen, H. (1985) A new type of papillomavirus DNA, its presence in genital cancer biopsies, and in cell lines derived from cervical cancer. EMBO J., 3, 1151-1157.

3) Dürst, M., Gissmann, L., Ikenberg, H. \& zur Hauzen, H. (1983) A papillomavirus DNA from a cervical carcinoma and its prevalence in cancer biopsy samples from different geographical regions. Proc. nat. Acad. Sci. USA, 80, 3812-3815.

4) Fukushima, M., Okagaki, T., Twiggs, L.B., Clark, B.A., Zachow, K.R., Ostrow, R.S. \& Faras, A.J. (1985) Histological types of carcinoma of the uterine cervix and detectability of human papillomavirus DNA. Cancer Res., 45, 3252-3255.

5) Hasse, A., Brahic, M., Stowing, L. \& Blum, H. (1984) Detection of viral nucleic acids by in situ hybridization. Methods Virol., 7, 189-226.

6) Maier, R.C. \& Norris, H.J. (1980) Coexistence of cervical intraepithelial neoplasia with primary adenocarcinoma of the endocervix. Obstet. Gynec., 56, 361-364.

7) Ostrow, R.S., Manias, D.A., Clark, B.A., Okagaki, T., Twiggs, L.B. \& Faras, A.J. (1987) Detection of human papillomavirus DNA in invasive carcinomas of the cervix by in situ hybridization. Cancer Res., 47, 649-653.

8) Pater, M.M., Dunne, J., Hogan, G., Ghatage, P. \& Pater, A. (1986) Human papillomavirus types 16 and 18 sequence in early cervical neoplasia. Virology, 155, 13-18.

9) Peters, R.K., Chao, A., Mack, T.M., Thomas, D., Bernstein, L. \& Henderson, B.E. (1986) Increased frequency of adenocarcinoma of the uterine cervix in young women in Los Angeles county. $J$. nat. Cancer Inst., 76, 423-428.

10) Reid, R., Greenberg, M., Jenson, A.B., Husain, M., Willett, J., Daoud, Y., Temple, G., Stanhope, C.R., Sherman, A.I., Phibbs, G.D. \& Lorincz, A.T. (1987) Sexually transmitted papillomavirus infection. I. The anatomic distribution and pathologic grade of neoplastic lesions associated with different viral types. Amer. J. Obstet. Gynec., 156, 212-222.

11) Schwartsz, S.M. \& Weiss, N.S. (1986) Increased incidence of adenocarcinoma of the cervix in young women in the United States. Amer. J. Epidemiol., 124, 1045.

12) Tase, T., Okagaki, T., Clark, B.A., Manias, D.A., Ostrow, R.S., Twiggs, L.B. \& Faras, A.J. (1988) Human papillomavirus types and localization in adenocarcinoma and adenosquamous carcinoma of the uterine cervix: A study by in situ DNA hybridization. Cancer Res., 48, 993-998.

13) Yoshikawa, H., Matsukura, T., Yamamoto, E., Kawana, T., Mizuno, M. \& Yoshiike, K. (1985) Occurrence of human papillomavirus types 16 and 18 DNA in cervical carcinomas from Japan: Age of patients and histological types of carcinomas. Jap. $J$. Cancer Res., 76, 667-671. 